\title{
Small Hydro Power Schemes: Technical Aspects
}

\author{
Hira Singh Sachdev, Ashok Kumar Akella \\ Department of Electrical Engineering, National Institute of Technology JSR, JH. 831014, India
}

\begin{tabular}{l} 
Article Info \\
\hline Article history: \\
Received Jan 12, 2016 \\
Revised Feb 14, 2017 \\
Accepted Feb 21, 2017 \\
\hline
\end{tabular}

\section{Keyword:}

Small hydro

Micro-hydro

\begin{abstract}
Small hydro systems play a major role in meeting power requirements of remote, isolated, hilly areas in a decentralized manner by tapping water streams, rivulets and canals of small discharge. Small hydroelectric system captures the energy in flowing water and converts it to electricity.

Of all the non-conventional renewable energy sources, small hydro stands first as it is more resourceful, reduces system losses, environment friendly, non-consumptive and source is renewable due to their enormous advantages over large hydro and other power plants, lot of small hydro-power plants have come up across the world to meet the ever increasing demand of electrical energy. Lowering the high initial cost of the small hydro-power plants and its popularization is today's challenges. This paper describes basic techniques design of the small hydro-power development.
\end{abstract}

Copyright $@ 2017$ Institute of Advanced Engineering and Science. All rights reserved.

\section{Corresponding Author:}

Hira Singh Sachdev,

Departement of Electrical and Electronics Engineering,

National Institute of Technology,

Jamshedpur, Jharkhand - 831014, INDIA.

Email: singhhira10@gmail.com

\section{INTRODUCTION}

Hydro electric development is now a well establishment technology and no new basic techniques have been developed in any particular country for SHP. However the details of development is being rationalized and simplified.

Micro Hydro Power Schemes are similar to any hydro electric scheme and can, therefore, be categorized in a corresponding manner on the basis of head as.

High head scheme

Medium head scheme and

Low head scheme

Further Hydro Power is also classified on the basis of source of water and its layout.

Run of river scheme - $\quad$ Development of a natural stream

Canal Scheme $\quad-\quad$ Development on a canal

Dam scheme $\quad$ - n Development on a dam

\subsection{Development and Design of Small (Micro) Hydro-Power Plants}

The primary objective of the design of the system is to improve the quality of power for a given load factor and to achieve this in an optimal way. This depends on parameters like the population, demand, and proximity to grid. A number of studies are available for design of both Grid connected and Stand-alone systems. Different techniques like optimization, simulation and other mathematical modeling tools have been used for this purpose.

Turner et al. [1] described the implementation of an $1150 \mathrm{~kW}$ Mini-Hydro Power plant at Wemind ji, a remote community in Northern Canada. The analysis of the overall costs of energy available to the 
community led to the selection of a mixed energy supply system consisting of mini-hydro power plant as the main element.

Prabil Raj et al. [2] found that of the renewable energy sources, SHP is the most attractive matured and reliable energy source for a country like India, where SHP potential of about 15,000 MW is available in canal falls, irrigation dams, run-of-the rivers and natural streams in the hilly regions. Only less than $6 \%$ of this potential i.e. about $900 \mathrm{MW}$ has been tapped so far.

Maher [3] stated that Pico Hydro Power has maximum capacity upto $5 \mathrm{~kW}$ and has the potential of providing energy to millions of rural people worldwide with a cheap and sustainable source of electricity. With the development of cost reduction approaches, e.g. local manufacturing and repair capability, pico hydro schemes might be adopted on a larger scale.

A methodology was developed by Sharma et al. [4] for finding optimum design discharge for Small Hydro Power (SHP) plants on the basis of benefits-cost (B/C) analysis by incorporating uncertainty in stream flows. A probabilistic hydrological model was developed which gave the optimum design discharge for SHP. The model can be extended to all the run of the river projects.

Taneja [5] highlighted that high line losses of long transmission lines, required to connect remote areas, makes extension of the grid prohibitive. Access to small clean energy is one of the basic human needs. Electricity is one of the cleanest forms of energy at the consumption stage. Electricity has a positive corelation with quality of life and prosperity .In India alone, only 55\% of households have access to electricity. Around 80,000 villages, still need to be electrified. The problem today is both quantative and qualitative. The villages do not get power in sufficient quantity and the quality of the power that they get is also very poor. As per the study of Planning Commission of India and UNDP, around 25\% land of our country is remote and has inhospitable terrain. These areas have low load density. Laying of long transmission lines, consequent high line losses make extension of the grid and consequent price of electricity very prohibitive. Off grid solutions like wind, solar, tidal and hydro-power etc can provide electricity to such areas where the grid cannot reach.

\section{COMPONENTS OF HYDROELECTRIC SCHEME}

Most of the hydro schemes in India are the high and medium schemes and have the following basic and common components: Figure. 1.

1. Diversion and Intake Structure

2. Water Conductor System

3. Desilting chamber

4. Forebay, Balancing reservoir and Spilling arrangements

5. Penstock

6. Power House Building Comprising of Turbine, Generator, Inlet Valve and other auxiliary systems like cooling water, drainage and dewatering systems, auxiliary power system and equipment, Emergency and Standby power system and equipment, Lighting system and equipment, Instrumentation Protection and Control system and equipment Ventilation system and Equipment, Station grounding, Fire fighting equipment and system.

7. Tail Race Channel

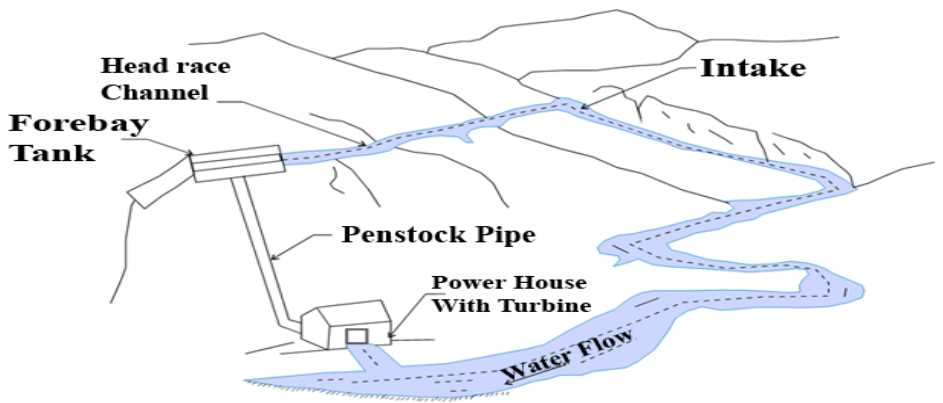

Figure 1. Diversion Hydroelectric [6]

However there are some hydro electric stations on irrigation canal and dams which are low head schemes.

\subsection{Generator, Voltage \& Frequency, Power Rating \& Speed}




\subsubsection{Generator}

The speed and frequency at which generator works must be specified because it concerns the internal working of overall unit.

There are two types of generator:

1. Induction generator

2. Synchronous generator

An induction generator requires external excitation; it is not used for isolated power plant. These generators are cheaper than synchronous generators. Efforts are on to provide electronics devices for excitation.

\subsubsection{Voltage}

For micro hydro power plants, single-phase generators are available with output voltage of $120 \mathrm{~V}$ and/or $240 \mathrm{~V}$ depending on internal connection, 3-phase generators are available for voltages of about $240 / 415 \mathrm{~V}$. If transformation of voltage is not being considered, the voltage generated should match that of the appliances and equipment that will be plugged into the system. If power will be transmitted some distance to the consumer. A higher generator voltage would reduce losses without requiring a transformer at the powerhouse and if both step-up and step-down transformers are being considered because of the magnitude of the power to be transmitted and the distance to be covered, either generation voltage could be used.

\subsubsection{Frequency}

The national usually sets the generator output frequency standard, which is either $50 \mathrm{~Hz}$ or $60 \mathrm{~Hz}$. In India frequency of $50 \mathrm{~Hz}$ is used.

\subsubsection{Power rating}

If a commercial unit is purchased and the net-head and flow available to a turbine have been determined. The output power is simply a function of unit's overall efficiency. The output of an AC generator is a current and voltage that both change in magnitude with time. If the external current is purely resistive, the current and voltage are in phase-at each point in time. The value of one is directly proportional to that of the other.

The average power output of the generator is equal to the power consumed by load:

$$
\text { Po }=\text { Eo Io }
$$

Where $\quad$ Po $=$ Effective Power $(\mathrm{VA}$ or $\mathrm{W})$

$$
\begin{aligned}
& \text { Eo }=\text { Effective Voltage (V) } \\
& \text { Io }=\text { Effective Current (I) }
\end{aligned}
$$

For a purely resistive type, the value of power expressed in watts is equal to the value expressed in volt-amperes. If the external circuit also includes inductive or capacitive elements, such as motors, transformers, or fluorescent lamps, the voltage and current may not be in phase.

$\mathrm{Po}=$ Eo Io Pf

Where Power Factor, $\mathrm{Pf}=\cos \phi_{\mathrm{pf}}$ and $\phi_{\mathrm{pf}}$ is a, measure of how much the voltage leads the current.

\subsubsection{Speed}

If generator is purchased separately, generator speed must be specified. The generator speed is related to the number of generator poles and the desired output frequency in the following manners:

$$
N=\frac{120 f}{n_{p}}
$$

Where $\mathrm{N}=$ Generator speed $(\mathrm{rev} / \mathrm{min}), \mathrm{f}=$ output frequency $(\mathrm{Hz})$ and

$\mathrm{n}_{\mathrm{p}}=$ no. of poles

Generally 4 poles are used to lower the speed and less gearing up is required. Six pole generators are costlier and used in plants in the range of 100-1000 kW.

\subsection{Physical Characteristics}

Small generators can either have brushes or be brusheless generators, an electromagnetic field transmits excitation current from the stationary to the rotating element, formerly, brushes rubbing against slip ring located on the shaft served for this purpose, but these wear out and have to be replaced periodically. Brusheless generators do not have affect the insulation of generator winding; it is also necessary to specify 
the climatic conditions. The types of coupling between turbine and generator should be specified. Direct coupling is preferred because it permits a more compact layout and less maintenance however it is impossible for small-standardized units. There are many types of coupling but the most suitable one must be chosen. If the generator experiences a loss of load or excitation, both the turbine and generator will attain a runaway speed.

\section{INTAKE STRUCTURE}

\begin{tabular}{|c|c|c|c|}
\hline River & Head Regulator & Power Channel & Forebay \\
\hline Water Source & Intake & Conveyance System & Desired Use \\
\hline Power Channel & Intake Structure & Penstock & wer House \\
\hline
\end{tabular}

An intake structure is an arrangement by which water is satisfactorily diverted for the required use. Thus, the intake is an arrangement which allows water to be taken from its source and then discharge into the conveyance system for which it is let to the desired use (e.g. hydro electric power generation).

Intake works should fulfill the following requirements.

1. Assured water supply

2. Suitable quality of water

3. Control over supply of water

Function requirements of intake remain the same but their layout, shape and operating arrangement will greatly differ according to their operating heads and according to the water conductor system.

According to operating head intake may be classified (a) Low head intake (b) Medium head intake and (c) High head intake.

\subsection{Canal Intake}

This intake can be situated at the river to transfer water from river to the channel. This is also known as head regulator. An intake provided in the power channel to hold the penstock shall also come in the category of canal intake which are low head intake.

\subsection{Dam Intake}

Intake is an integral part of the dam structure and can be possible only in concrete dams. In case intake required on an earth or rockfill dam, the conveyance system will be generally tunnel. Dams intakes will be generally low and medium head intake.

\subsection{Choice of Location}

In Intake from river feeding head race channel/tunnel is silted or straight reach of the river, the ratio of sediment carried into diversion channel and the main stream is much more as compared to the ratios of respective discharges, e.g. 50-50\% discharge in the two, bed load entering the diversion channel may be $90 \%$. Angle of off takes does not have significant effects. However, sediment entry into the diversion channel will be greater with $30^{\circ}$ as compared to $90^{\circ}$.

At the bends, on account of combined effect of velocity distribution in a vertical and corresponding centrifugal force, a sort of spiral flow is set and simultaneously cross flows develops at the cross sections velocities decreasing towards convex side. The flow pattern also induces segregation in the bad load. River fraction of sediment load will be more along circular path concentric with the curve while the courser ones get directed towards the curve peak where they got entrapped in the spiral flow and transported off the concave bank. Therefore, intake located on the concave side of a curve at point, where spiral flow is strong will draw comparatively silt free water. It is seem that sitting the intake at the downstream end of the curved stretch is the most favourable because the spiral flow will be less and is raised by diversion work, the velocity of flow will be less and the centrifugal force acting on water masses moving in bend is diminished and spiral flow is developed. Model study is recommended in individual case to determine the best site for an intake.
4. TYPE OF WEIRS
a. Trench weir
b. Rock fill weirs
c. Vertical drop weirs
d. Concrete weir with sloping glacis
4.1. Rock Fill Weirs 
Boulders are laid in the weir intervening walls. The downstream slope is generally made in flat slopes.

\subsection{Vertical Weirs}

Concrete masonry gravity overflow weir is constructed over the river bed with energy dissipation arrangements.

\subsection{Concrete Weirs with Sloping Glacis}

Weirs of this type are of recent origin and their design is based on modern concept of sub surface flow. Sheet piles of sufficient depths are driven at upstream and downstream and some time at intermediate location.

\subsection{Design Considerations}

The design weir in two phases.

1. Hydraulic Design,

2. Structural design

Hydraulic Design: Deals with the evaluation of the hydraulic forces acting on the structure and determination of the configuration of the same for the best economy and efficiency.

Structural Design: consists of the different part of the structure to enable it to resist safety from all the forces acting on it.

\section{DESILTING ARRANGEMENTS}

Even since the present canal system controlled by head works care into existence, the engineers have been facing the problems of silting of the off-taking channels during monsoons. Streams especially originating from Himalayas, carry a large quantity of sediments consisting of boulders, pebbles, single and sand. This excessive sediment is not carried down by the off taking channels due to their slope being milder than that of the streams. The channel thus tends to aggregate resulting in reduction of its discharging capacity in the power channels, the sediment laden water damages the runner blades of the turbine, thereby affecting the power generation. The sediment deposited in the channels if has to be removed manually necessitating long closure with inevitable loss of revenue.

Various measures have been evolved from time for checking entry of sediment into the off taking channels.

These can be broadly classified into:

1. Preventive: The entry of sediment checked before its entry into the head regulation. These are constructed in the streams.

2. Curative: The sediment is excluded from the channel after its entry with the channel. These are constructed in the channel.

The basic principle on which these devices work is that in a mobile channel the sediment is transported, as bed and suspended load. The vertical eddy component of the current throw up the finer particles which are held in suspension moves along the bed by rolling, sliding and saltation. There is not clear line of demarcation between the bed load and suspended load due to continuous inter change of particles leaving and returning to the bed. The concentration of material in lower layers is however greater than that in the upper ones. Therefore, the water extracted from the lower layers carries comparatively more sediment, thereby reducing the sediment concentration in the canal downstream.

\subsection{Setting Basins}

Setting basin in one of the most effective devices for removing sediment particles from the flowing water. The reduction in the velocity of flow in the settling basin is caused by expansion of the channel cross section over the length of the basin. Such reduction in the velocity also reduces the bed shear stress and the turbulence. Reduction in the velocity, shear stress and the turbulence, if adequate, steps the bed material from moving and also causes part of the suspended material to deposit. Once the minimum size of sediment to be removed has been decided, the design of the settling basin involves determination of the depth and length of the basin and choice of the method of removal of the deposited material.

The mean horizontal velocity in the settling basin that is considered desirable depends on the smallest size of sediment to the removed and the economic length of the basin. The velocity in the existing settling basins ranges from 0.08 to $0.45 \mathrm{~m} / \mathrm{s}$. The smaller velocity should be used if finer material is to be removed. Since vary long settling basins are needed for removing.

\section{TYPES OF POWER CHANNEL}




\subsection{Open Channel}

(a) Rectangular

(b) Trapezoidal

(c) Triangular

\subsection{Closed Conduit}

(a) Reinforced concrete pipe

(b) PVC pipes

(c) Steel pipes

\subsection{Flumes/Covered Channels}

The feeder channel or channel near intake should be preferably covered/RCC box section because this area may be subjected to flood.

\subsection{Alignment}

In general for the alignment of channels, following principles must be followed -

(a) The canal length should be as short as possible.

(b) The canal should be aligned as high as possible usually along the contours so as to gain more head.

(c) To cross-drainage works such as aqueducts, flumes etc. should be avoided as far as possible.

\subsection{Materials For Lining}
(a) Stone Masonry
(b) Concrete lining
(c) Lining with LDPE
(d) Shortcrete lining
(e) Brick tiles lining
(f) RCC section

\section{FOREBAY}

The forebay is a basin located just before the entrance to the penstock. Possible design ranges from a simple excavated area or pond to a structure of reinforced concrete.

\subsection{Purposes f Forebay}

The forebay can serve following purposes:

(i) It can serve as a final settling basin where any water borne debris which either passed through the intake or was swept into the canal can be removed before the water passes in to the turbine.

(ii) The forebay provides some storage in case of sudden failure of the system.

(iii) To spill the water in case of sudden shut down or extra water coming to forebay during rains etc.

\subsection{Components of Forebay}

(i) Basin

Depending upon the purposes of Forebay, it may have following components -

(ii) Spillway

It is to provide storage as well as for settling the debris.

On occasion the flow entering the forebay may exceed the flow leaving via penstock, such as when a gate at the intake has been set improperly, when the valve to the turbine has been closed or during heavy rains when excess water enters the canal from the stream or from runoff from the uphill. For these reasons, it is advisable to have spillway.

(iii) Gate or Valve (iv) Outlet

A gate or valve must be provided at the entry to the penstock to control the flow to the penstock.

An outlet must be provided top drain the silt accumulated in the forebay. This outlet may be gate compelled or valve controlled.

(v) Trashrack

Trashrach is included in the forebay to prevent the flow of debris into the penstock. 
(vi) Air Vent

An air vent pipe is included in the wall of the forebay just before inlet to the penstock. This is provided as a safety precaution against collapse of the penstock during penstock gets emptied and pressure falls below atmospheric. The area of air vent pipe $=1$ to $2 \%$ of penstock area.

\subsection{Location of Forebay}

The location of the forebay is governed by topographical and geological conditions of the site. However, the site of the forebay and power house should be so selected that the penstock has minimum length.

\subsection{Storage}

The forebay is usually designed for a storage of 2 minutes. A dead storage of about $0.5 \mathrm{~m}$ depth is provided below the penstock entry to account for silt accumulation etc.

\subsection{Bell Mouth Details}

To have uniform flow, the entry to penstock is bell mouthed.

\section{PENSTOCK}

Various types of material are nowadays available for manufacturing the pipes which could be used as penstocks for small hydropower development in the country. The merits and demerits of these pipes very widely. For making the selection of type of pipe should be used for the specific site, several factors such as basic cost, transportation and erection art and availability of material and skill should be considered thoroughly and a comparative analysis shall lead to the designer to make some decision.

Design of Penstock: (1) Criterion for Hydraulic Design of Penstock IS 11625-2014

(2) Criterion for structure design of Penstocks IS 11639 (Part I) - 2014

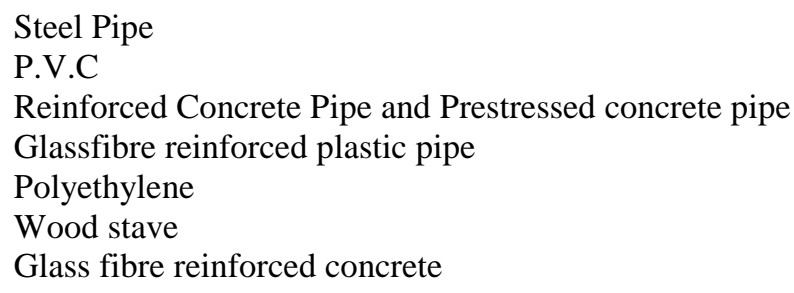

\section{POWER HOUSE BUILDING}

Power house building for small hydro power stations essentially requires a big hall to accommodate machine (turbines Generators etc.) with sufficient height to accommodate carne operations, and sufficient space for maintenance and control operations. It can be constructed as a steel structure consisting of columns, beams trusses etc. or it can be Reinforce concrete formed structure with gable grames to accommodate roof (Purlins, sheeting etc). For remote hilly sites prefab buildings can also be used which are easy to transport and quick installation.

\subsection{General Layout of Power Station}

In General, a power station may be divided into four areas:

(i) The main machine hall (Unit bay)

(ii) Erection bay

(iii) Control bay

(iv) Other services areas

\subsection{Prefab Buildings}

For remote hilly areas prefab buildings in component from is a modern technique. These are quick to erect and easy to transport and store in component form.

The prefab units consist of cold form steel structural member like purlins, teel rails, insulated load bearing wall panels with outside cladding m.s. profiled sheets and inside plastic/cement board, insulated ceiling panels and partition panels, aluminum corrugated 22 guage sheets for roofing, pressed steel door frames and windows. 
This roof of building can be safely designed for following design parameters.

$\begin{array}{llll}\text { (i) } & \text { Seismic coefficient } & - & \text { Seismic zone V } \\ \text { (ii) } & \text { Wind Pressure } & - & 150 \mathrm{~kg} / \mathrm{m}^{2} \\ \text { (iii) } & \text { Temperature } & - & (-) 40^{\circ} \mathrm{C} \text { to } 55^{\circ} \mathrm{C}\end{array}$

\section{ESTIMATION OF MICRO HYDRO POTENTIAL/ NATURE OF LOAD}

10.1. Micro Hydro Power (MHP)

Micro hydropower is cheapest source of electric power and can be estimates as:

$$
\mathbf{P}_{\text {MHP }}=\mathbf{0 . 0 0 2 2} \text { Wr. H } \quad(\mathbf{k W h} / \text { year })
$$

Where $P_{\text {SHP }}=$ Electrical Energy from small hydro power plant (or electric station)/year

$\mathrm{Wr}=$ Useful water in reservoir in a year, $\mathrm{m}^{3}$

$\mathrm{H}=$ Effective head, $\mathrm{m}$

(Useful water in reservoir is only about upper $15 \%$ to $20 \%$ )

\section{Distribution Area (Energy Flow Diagram)}

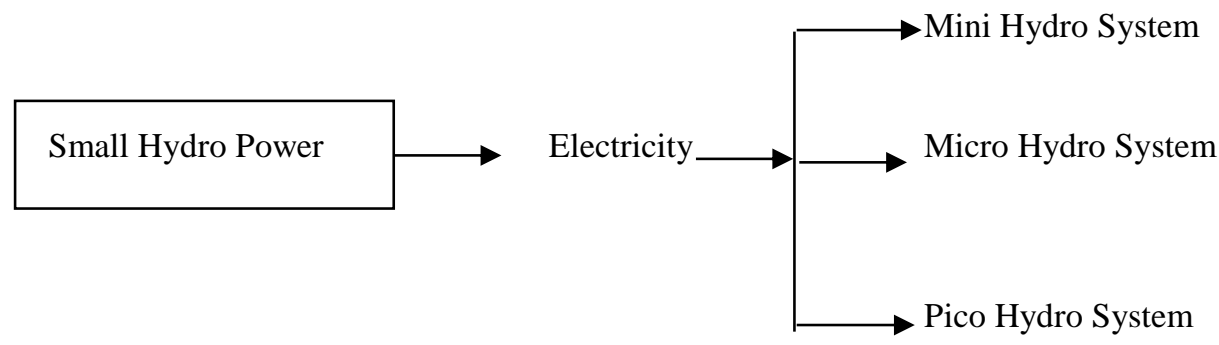

(Generation Area)

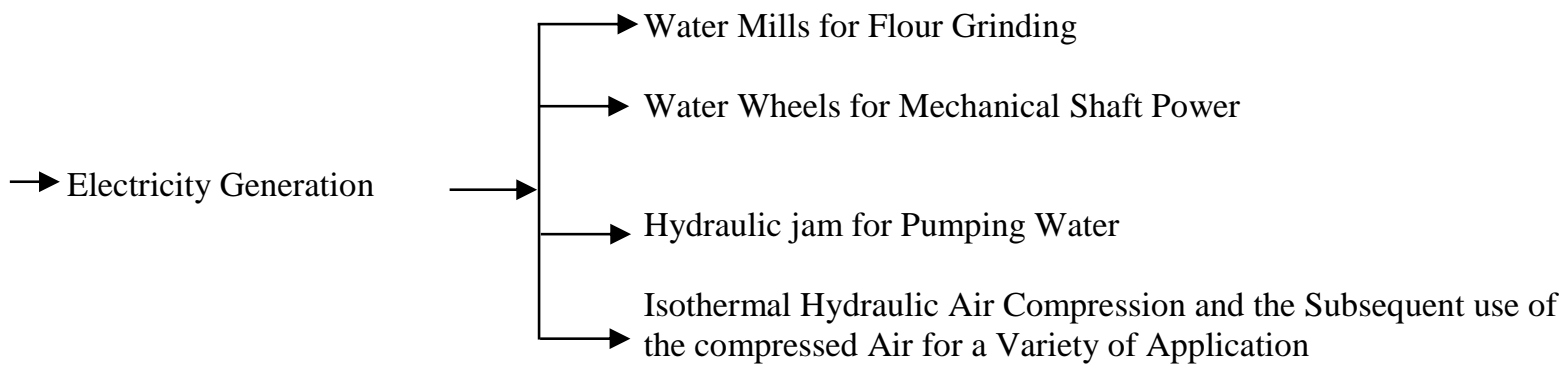

(Consumption Area)

\section{CONCLUSION}

Where a hydropower resource exists, experience has shown that there is no more cost-effective, reliable and environmentally-sound means of providing power than a hydropower system.

Small Hydro projects are, environmentally benign, have relatively short gestation periods, and require small investments as compared to large hydro projects.

Small Hydro provides a solution to rural electrification, poverty alleviation.

Small Hydro has proven technology, low risk for investment.

Small Hydro does not involve setting up of large dams or problems of deforestation, submergence or rehabilitation.

To capture and efficiently utilize the small hydro energy in today's energy market requires multistage integration of several factors, including proper matching design of the hydro energy resources and energy demands of a particular region.

\section{ACKNOWLEDGEMENTS}


The authors are thankful to All India Council of Technical Education (AICTE), Ministry of Human Resources Development (MHRD), Govt. of India for providing financial assistants to do the research work under Quality Improvement Programme (QIP).

\section{REFERENCES (10 PT)}

[1] Turner B., Simpson R.J., Gillaud Ch., (March 1988), "Developing A Mini-Hydro plant in the Remote Canadian North", IEEE Trans. on Energy Conversion, Vol. 3, Issue No. 1, pp. 18-25.

[2] Prabil Raj C.P., Mohapatra N.K., (1998), "Micro Hydro-A Mega VISION (Case Study)", Proceeding of the National Seminar on Energy Technologies for sustainable Development, BIT Sindri, Ranchi, pp. 205-221.

[3] Maher P., (1998), "Pico Hydro Power for Rural Electrification in Developing Countries", Internal Journal of Ambient Energy, Vol. 19, Issue No. 3, pp. 143-148.

[4] Sharma M.G., Das D.D., Sharma J.D., (July-August, 2001), "Selection of optimum discharge for run of river power plant”, Indian Journal of Power \& River Valley Development, pp. 149-153.

[5] Taneja V., (2006), "Community Participation in SHP Development", Himalayan Small Hydro-power Summit, Dehradun, October, 12-13.

[6] Website: http://www.alternative-energy-news.info/technology/hydro.com

[7] D. Rai, " Non-Conventional ENERGY SOURCES" Khanna Publishers, 2-B, Nai Sarak, Delhi, pp. 370.

[8] S. Rai, "ENERGY TECHNOLOGY Non-conventional, Renewable and Conventional", Khanna Publishers, 2-B Nath Sarak, Delhi, pp. 976-977.

[9] Rama Kumar R., (1993), "Economic Aspects of Advanced Energy Technologies", Proceeding of the IEEE, Vol. 81, No. 3, pp. 318-332. 